\title{
O papel do tutor virtual na educação a distância
}

The role of the virtual tutor in distance education

Márcia Gorett Ribeiro Grossi* Centro Federal de Educação Tecnológica de Minas Gerais

José Wilson Costa** Centro Federal de Educação Tecnológica de Minas Gerais

Mércia Maria Moreira***

Centro Federal de Educação Tecnológica de Minas Gerais

Resumo A Educação a Distância (EaD) vem ganhando destaque na sociedade atual devido a emergência das tecnologias da informação e a necessidade, cada vez maior, de conhecimento. Entendendo que as tecnologias usadas nos cursos a distância, por si só, não garantem o sucesso desta modalidade de ensino, destaca-se a figura do tutor virtual. Nesta perspectiva o objetivo desta pesquisa foi verificar as funções do tutor virtual como coadjuvante no processo de ensino e aprendizagem, bem como os limites do seu exercício profissional através de um estudo de caso em duas instituições de ensino, uma publica e outra particular. Foi possível compreender algumas características peculiares do trabalho da tutoria virtual, e fazer algumas inferências sobre a necessidade de um olhar mais atento para as atividades desses profissionais e para a sua regulamentação.

PALAVRAS-CHAVE: Tutoria virtual, Educação a distância, Funções do tutor virtual.

Abstract The Distance Education is gaining prominence in today's society, due to emergency of the information technologies and the increasing need for knowledge. Considering that the technologies used in distance education will not ensure the success of this teaching modality theirselves, we highlight the figure of the virtual tutor. In this perspective, the objective of this research was to investigate the functions of virtual tutor as an adjunct in the process of teaching and learning, as well as the limits of their professional practice, through a case study in two schools, one public and one private. It was possible to understand some peculiar characteristics of the virtual tutors' work and to make some inferences, specially about the need for a closer look into the activities of such professionals and their regulamentation.

KEYWORDS: Virtual tutoring, Distance education, Virtual tutor functions. 


\title{
Introdução
}

A Educação a Distância (EaD) é definida por Moran (2002) como um processo de ensino eaprendizagem, mediado por tecnologias, nas quais professores e alunos estão separados espacial e/ou temporalmente. É ensino e aprendizagem em que professores e alunos não estão normalmente juntos, fisicamente, mas podem estar conectados, interligados por tecnologias, sendo a internet atualmente a principal. Mas também podem ser utilizados os correios, o rádio, a televisão, o vídeo, o CD-ROM, o telefone, o fax dentre outras.

São muitas as definições sobre esta modalidade de ensino, como a apresentada por Moore e Kearsley (2007):

\begin{abstract}
é o aprendizado planejado que ocorre normalmente em um lugar diferente de local do ensino, exigindo técnicas especiais de criação do curso e de instrução, comunicação por meio de várias tecnologias e disposições organizacionais e administrativas especiais. (MOORE; KEARSLEY, 2007, p. 2)
\end{abstract}

A Educação a distância não é uma modalidade de ensino recente, mas, com o surgimento da internet, tornou-se necessário repensar as metodologias adotadas nos cursos de EaD, pois segundo Moreira (2005), a internet permite a alteração da dimensão da noção de aula e a possibilidade da aprendizagem é amplamente resignificada, superando a idéia de que a aula só poderia acontecer na forma presencial, permitindo um sentido mais amplo e democrático às relações pedagógicas.

E, para oferecer uma EaD de qualidade é necessária uma equipe multidisciplinar que possa explorar a variedade de ferramentas tecnológicas existentes e as diversas formas de interação entre os atores envolvidos nesta modalidade de ensino, buscando assegurar o sucesso do processo ensino e aprendizagem. Nessa perspectiva, pode-se considerar de grande importância uma configuração institucional adequada aos cursos a distância, juntamente com as tecnologias para a mediação dos conteúdos. Assim, se percebe a necessidade da atuação conjunta de diferentes atores, tais como: professor formador; professor conteudista, professor pesquisador; tutor presencial, tutor virtual (tutor a distância), coordenadordecurso ou coordenadorpedagógico, coordenadordepólo, pedagogo e designer instrucional.

Para cada um desses atores existe uma responsabilidade necessária a fim de garantir o funcionamento adequado e requerido pela EaD. Neste estudo, o foco está no tutor virtual, que é o profissional quem fará orientação e acompanhamento das atividades realizadas on line pelos alunos, por meio do Ambiente Virtual de Aprendizagem (AVA), tirando dúvidas e corrigindo tarefas, dentre outras funções.

Mas, na prática, tem acontecido um debate permanente sobre a figura da tutoria. Quais são suas funções e seus limites, quais as diferenças entre suas atividades e as do professor. Sem dúvida essas questões permeiam as discussões 
no interior dos projetos de educação a distância. Muitas vezes, há conflitos sobre a autonomia, a flexibilidade na realização de atividades tutoriais dentro do curso, bem como sobre a hierarquia entre professor e tutor.

Nesta perspectiva, o objetivo desta pesquisa foi verificar as funções do tutor virtual, como coadjuvante no processo de ensino e aprendizagem, bem como os limites do seu exercício profissional. Para alcançar esse objetivo foi realizado um estudo de caso em duas instituições de ensino que oferecem cursos a distância, uma pública e outra particular.

\section{O papel do tutor virtual: alguns pressupostos}

A tutoria no contexto virtual

Diante da estrutura organizacional dos cursos a distância na modalidade on line através das classes virtuais com base na internet, o trabalho do tutor virtual e suas interações com os outros atores, que configuram o curso em que atua, adquire relevância fundamental. A tutoria ganha grande importância nesse contexto virtual de aprendizagem por ser responsável por assegurar as comunicações bidirecionais entre tutor-aluno e aluno-professor, comunicações que são essenciais para que ocorra a construção do conhecimento.

Para tanto, é necessário que o tutor acompanhe o desenvolvimento do aluno e possua uma grande habilidade e agilidade nas respostas e retornos dados aos mesmos. Principalmente porque a comunicação entre estes, no ambiente virtual, nem sempre acontece sincronicamente. Na grande maioria das vezes, esta comunicação é assíncrona, mas o retorno às demandas dos alunos, que vêm o ambiente virtual como a sua sala de aula, deve ser o mais rápido possível.

Possuindo tamanha relevância neste contexto virtual de aprendizagem, busca-se aprofundar a compreensão o papel da tutoria nas relações aluno-objeto do conhecimento. Porém, não é possível definir uma concepção única de tutoria, uma vez que essa varia em decorrência do projeto pedagógico do curso e da instituição no qual está inserido.

A tutoria virtual como facilitadora da interatividade

Para Silva (2001), interatividade é um conceito de comunicação, e não de informática, podendo ser empregado para significar a comunicação entre interlocutores humanos, entre humanos e máquinas e entre usuário e serviço.

Utilizando esta definição no contexto da EaD, a interatividade faz-se relevante, pois oportuniza novas relações com o conhecimento, com o uso dos recursos tecnológicos e midiáticos e ainda com os outros atores como: aluno-aluno, aluno-tutor e aluno-professor. Nesta modalidade de ensino, a interatividade se faz necessária não apenas como troca de comunicação, mas também pela geração de conteúdo (RICHARDS, 2006). 
Assim, Anderson (2003) define a interação na educação a distância como sendo:

\begin{abstract}
um conceito complexo e multifacetado em todas as formas. Tradicionalmente interação focava na interação entre professores e alunos em sala de aula. Esse conceito foi expandido para incluir diálogos sincronizados a distancia (conferência de áudio e vídeo); formas assíncronas de diálogo simulado e diálogo assíncrono mediado (conferencia por computador e correio de voz); e respostas e retornos de objetos e dispositivos inanimados, tais como "programas de computador interativos" e "televisão interativa". (ANDERSON, 2003, p. 129)
\end{abstract}

Como acontece em todas as modalidades de educação, a aprendizagem na EaD não é um ato solitário e isolado, ele perpassa campo das relações sociais em movimentos de trocas contínuos, nos quais há o compartilhamento de saberes e experiências entre os atores envolvidos no processo ensino e aprendizagem.

E, esse processo torna-se cíclico, já que a partir da convivência virtual os AVA's, utilizados na EaD, oportunizam as trocas de informações e (re)significam conceitos entre os participantes deste processo, num movimento sucessivo, no qual cada um deixa sua marca e é marcado pelos outros.

De acordo com Mussi e Haguenaur (2009) citado por Silva (2001) o processo de interatividade é a superação da transmissão unilateral do ensino:

interatividade significa libertação do constrangimento diante da lógica da transmissão que dominou no século XX. É o modo de comunicação que vem desafiar a mídia de massa - rádio, cinema, imprensa e TV a buscar a participação do público para se adequar ao movimento das tecnologias interativas. É o modo de comunicação que vem desafiar professores e gestores da educação, igualmente centrados no paradigma da transmissão, a buscar a construção da sala de aula onde a aprendizagem se dá com a participação e cooperação dos alunos (...) Vivemos a transição do modo de interação massivo para o interativo. (SILVA, 2001, p. 1)

Neste sentido, a responsabilidade por garantir a interatividade nos AVA's cabe a todos os atores envolvidos com a EaD, mas principalmente aos tutores virtuais, pois estes ao perceberem a importância da edificação do conhecimento por meio das relações sociais efetuadas nos AVA's deverão direcionar, juntamente com os professores, as práticas pedagógicas para atividades que contemplem a interatividade entre os sujeitos. Construindo assim um percurso pedagógico marcado pela dialogicidade, uma vez que a interatividade depende muito mais da sensibilidade e interferência humana do que das ferramentas tecnológicas. 


\section{O Professor e o tutor virtual}

De acordo com Moreira (2005):

o professor é o grande mediador do processo de construção de conhecimento. Nessa posição, algumas de suas funções são a de criador, participe e avaliador de situações didáticas que satisfaçam as necessidades e interesses dos alunos e possam, assim, mobilizá-los para lidar com problemas, projetos, temas e situações de aprendizagem, em ambientes virtuais de máxima interação possível. A ele compete, portanto, elaborar os materiais didáticos; selecionar conteúdos, que devem ser sempre atualizados; averiguar a funcionalidade do planejamento, fazendo os ajustes necessários; estimular a interação e, sobretudo, estimular a apresentação, discussão e possíveis soluções para problemas que se apresentem ao longo do processo ensino aprendizagem. (MOREIRA, 2005, p. 3)

Nesse contexto, os tutores estão sempre atuando junto com os professores. De acordo com Moreira (2005) existem dois tipos de tutores, de acordo com a condução dos cursos em EaD. São eles:

10) Tutores que não exercem a função docente: esse tutor tem um papel de coadjuvante do professor no sentido de que, contribui com ações que propiciam o aumento das chances de sucesso do aluno no processo ensino e aprendizagem. Nessa categoria, o tutor deve:

- ser referência de apoio ao estudante, procurando, de acordo com os conhecimentos que irá obter antes e durante o curso sobre o aluno, ser capaz de elaborar estratégias e instrumentos com o objetivo de ampliar as chances de aprendizagem;

- mediar relações entre a coordenação e os professores;

- fazer com que os alunos desenvolvam atitudes favoráveis à construção do conhecimento. Nesse processo, a motivação do aluno deve ganhar grande enfoque;

- procurar estabelecer um clima de confiança entre os entre os integrantes do curso de forma a alcançar os objetivos propostos pelo curso;

- orientar e resolver dúvidas dos estudantes em todo seu percurso, do início ao fim do curso.

$\left.2^{\mathbf{o}}\right)$ Tutores que exercem a função de professor: esse tutor ministra cursos a distância, e deve possuir perfil e atuação que, a rigor, não difere do professor que atua na modalidade do ensino presencial. Dentre os requisitos para essa função estão:

- conhecimento do conteúdo;

- formação pedagógica relativa ao manejo e organização de classes;

- conhecimento curricular;

- visão crítica dos conceitos educacionais, suas raízes históricas e filosóficas. 
Ainda segundo essa autora, a atuação do tutor virtual deve ter como base o estudo das Ciências Sociais, da Didática, da lingüística, da Psicologia Cognitiva e da Antropologia Social para que possam fazer emergir, compreender e conduzir novos modos de trabalho entre aluno e professor com bases mais sólidas.

O tutor-professor, ao exercer esse papel, deve possuir clareza em relação aos objetivos do curso para que possa selecionar e organizar conteúdos, principalmente que seja capaz de identificar os principais aspectos que pretende construir como conhecimentos básicos. Além disso, é essencial para o processo de construção do conhecimento que o tutor considere os conhecimentos prévios dos alunos, para, a partir desta compreensão, definir os conteúdos e estratégias necessárias para o processo ensino e aprendizagem.

Os tutores que exercem essa função a fazem por diversos motivos: número excessivo de alunos, situação freqüente nessa modalidade de ensino, falta de disponibilidade de tempo do professor para interagir com os alunos da forma desejável. Contudo, deve ficar claro que é o professor quem deve ser responsável pelo material didático que será usado no curso e, ser o orientador e supervisor do trabalho educativo desenvolvido.

Para potencializar as chances de sucesso da EaD, alguns pressupostos devem nortear o trabalho dos tutores-professores. São eles:

- os conhecimentos são resultantes de uma construção, com uma dimensão histórica. Essa dimensão deve ser considerada, na construção de novos conhecimentos, como na transmissão de conhecimentos já instaurados. Levando isso em consideração é importante compreender que os conhecimentos não são verdades inquestionáveis;

- oaluno deve possuir papel ativo nas situações de ensino eaprendizagem com a intencionalidade de que a aprendizagem seja melhor construída e internalizada, sempre, levando em conta suas individualidades culturais e sociais, interesses e disponibilidade para interação com os outros atores do curso;

- propiciar o envolvimento afetivo do aluno com seus colegas nas relações de ensino e aprendizagem por meio do desenvolvimento de atividades em grupos;

- objetivando o desenvolvimento da autonomia do aluno, o tutor deve fazer uso de atividades cooperativas, como exemplo, promover a participação em grupos de discussão e participação em redes interativas; - fomentar a discussões de questões e problemas e encorajamento para descobrir soluções através da mediação do professor de forma significativa;

- comoadvento da internetedeoutras tecnologias digitais, possibilitando assim uma grande variedade de interações, o tutor redefine o seu papel, sendo facilitador, instigador e, muitas vezes, colega e colaborador;

- valorizar a diversidade cultural que existe em um curso a distância;

- buscar novos programas (softwares) educativos, que atendam às avançadas demandas de propostas em EaD que reforcem sua qualidade e sua proposta de democratização. 


\section{Procedimentos metodológicos}

\section{O estudo de campo do cenário da tutoria da EAD}

Para verificar a função da tutoria virtual na modalidade de cursos em EaD foram pesquisadas, no ano de 2010, duas instituições de ensino que são referências no desenvolvimento de cursos a distância, uma pública (denominada instituição A) e outra particular (denominada instituição B), ambas localizadas na cidade de Belo Horizonte - Minas Gerais.

As duas instituições aceitaram bem a pesquisa e foi explicado aos coordenadores dos cursos a distância o objetivo da pesquisa, ou seja, conhecer a tutoria em suas várias dimensões. Para isso utilizou-se como instrumento de coleta de dados duas técnicas conjugadas: a observação (para se ter uma visão mais ampla do universo pesquisado) e questionários (que foram distribuídos aos tutores virtuais e aos coordenadores dos cursos, os quais possuíam questões diferenciadas para cada ator).

A partir do material coletado, se organizaram os dados, visando à categorização dos mesmos para uma melhor compreensão do cenário da tutoria. Tabulou-se todos os itens do questionário que possuíam questões estruturadas em uma tabela de dupla entrada - itens do questionário $X$ sujeitos - e utilizou-se a técnica de análise de conteúdo nos itens abertos.

\section{Apresentação dos resultados}

\section{a) As instituições observadas}

- Instituição A: Oferece cursos de graduação, atualização e especialização na modalidade a distância. Seu espaço físico é destinado tanto para a modalidade a distância como para a presencial, ou seja, não possui um núcleo de educação a distância (NEAD). Além disso, possuem poucas salas disponíveis com computadores. Talvez, por esse motivo, foi difícil encontrar os tutores virtuais. Possuem uma equipe tecnológica que oferece consultoria, portanto, não estão alocados na instituição. Fazem uso de software livre. Não possuem equipamento para gravação de videoconferência nem de vídeo-aula.

- Instituição B: Oferece cursos de graduação, atualização e especialização na modalidade a distância. Já o espaço físico desta instituição é totalmente destinado ao trabalho com a Educação a distância, possuem um NEAD. Seus profissionais estão diretamente relacionados com essa modalidade. Suas secretarias são divididas por categorias de cursos: graduação, atualização, especialização. Possui extenso arcabouço tecnológico, como exemplo, diversas salas contendo computadores, centralizando, ali, todas as suas atividades. Trabalham com software próprio, desenvolvido especificamente para esta instituição. Possui equipe de design gráfico, equipe de apoio tecnológico, suporte telefônico e on line aos alunos, espaço para gravação de vídeo-aula, videoconferências. 


\section{b) Perfil dos tutores a distância}

Em ambas as instituições, a maioria do tutores virtuais é do sexo feminino. Dos oito tutores virtuais que participaram da pesquisa na instituição A, $62 \%$ são do sexo feminino. Na instituição $B$ (que possui 31 tutores virtuais) a porcentagem é quase a mesma: $63 \%$.

Quanto à idade, a variabilidade é grande nas duas instituições. Na instituição A faixa etária dos tutores varia de 28 a 53 anos, sendo que a maioria dos tutores, $75 \%$ estão na faixa etária entre 28 e 37 anos. Na Instituição B a variabilidade é de 25 a 65 anos e com $80 \%$ dos tutores na faixa etária entre 25 e 39 anos. A média aritmética das idades dos tutores na instituição $A$ é de 35 anos e na instituição B é de 38 anos, muito próximas.

Quanto à escolaridade dos tutores virtuais, na instituição $A, 25 \%$ possuem curso de especialização; $12,5 \%$ possuem doutorado e $62,5 \%$ possuem outros cursos. Na instituição B $20 \%$ possuem graduação; 70 \% possuem especialização e $10 \%$ possuem mestrado.

Em ambas as instituições todos os tutores virtuais trabalham na sua área de formação.

\section{c) Situação funcional dos tutores a distância}

- Vinculo empregatício: A porcentagem de tutores virtuais da instituição A que informaram não possuir nenhum vínculo empregatício com a instituição foi de $87,5 \%$ e, não foi informado o tipo de vínculo estabelecido. Nenhum dos tutores desta instituição recebe algum tipo de benefício, tais como: plano de saúde, vale transporte, vale refeição. Já, todos os tutores da instituição B possuem vínculo empregatício com a instituição, sejam como instrutores ou como agente administrativo; $40 \%$ recebem planos de saúde e vale transporte; $5 \%$ recebem apenas plano de saúde; $33 \%$ recebem apenas vale transporte; $3 \%$ recebem apenas vale refeição e $7 \%$ não recebem nenhum benefício. Pela análise das questões abertas, observou-se que existe um alto grau de insatisfação por parte dos tutores virtuais, pois suas funções não são consideradas como sendo docente e sim administrativa. A seguir algumas falas destes tutores:

Ainda percebo que os tutores, de modo geral, dedicam muito a tarefas que deveriam caber somente aos professores, o que acarreta uma sobre carga que prejudica o acompanhamento dos alunos.

Seria de grande valia que o tutor fosse reconhecido como profissional da educação e não do quadro administrativo.

Se o tutor corrige atividades, provas, pontua o aluno, ele deveria ser, no mínimo, reconhecido como professor. 
- Faixa Salarial: Observou-se que os salários pagos aos tutores virtuais da instituição $A$ são bem menores que os salários pagos pela instituição B, como pode ser observado na tabela 1 . Na instituição $A, 75 \%$ dos tutores declararam estar insatisfeitos e muito insatisfeitos com o salário e, $25 \%$ estão satisfeitos e muito satisfeitos. Já na instituição B, $70 \%$ estão satisfeitos e $30 \%$ insatisfeitos e muito insatisfeitos. Em relação a estes dados, vale observar que alguns tutores virtuais justificam a satisfação com o salário porque afirmam que estão aprendendo com a função além de obterem alguma remuneração. Os tutores mais insatisfeitos são aqueles com mais tempo na função e os mais satisfeitos são os que estão há menos tempo.

Estes dados podem explicar o porquê das avaliações com baixo grau de satisfação dos tutores em relação à remuneração. Pela fala dos tutores virtuais percebe-se a insatisfação:

Pela nossa função e responsabilidade, ganhamos muito pouco se comparados aos professores do nível básico. O reconhecimento pela instituição do trabalho do tutor, a meu ver, é também através de remuneração.

Tabela1: Faixa salarial dos tutores virtuais

\begin{tabular}{c|c|c}
\hline Faixa salarial & Instituição A (\%) & Instituição (B) \\
\hline Menor que $\$ 500,00$ & 0 & 0 \\
\hline Entre $\$ 500,00$ a $\$ 1000,00$ & 100 & 40 \\
\hline Entre $\$ 1000,00$ a $\$ 1500,00$ & 0 & 43 \\
\hline Entre $\$ 1500,00$ a $\$ 2000,00$ & 0 & 17 \\
\hline Acima de $\$ 2000,00$ & 0 & 0 \\
\hline
\end{tabular}

- Número de horas trabalhadas: Em relação ao número de horas de trabalho, os tutores virtuais da instituição A possuem contrato de 20 horas semanais e $75 \%$ afirmaram não trabalhar além das horas contratadas; $25 \%$ afirmaram que trabalham muitas horas a mais, sendo que um dos tutores respondeu que trabalha 30 horas semanais a mais (tabela 2). Os tutores da instituição B são contratados em diversas modalidades de horas semanais e $50 \%$ deles afirmaram que trabalham além das horas contratadas. A variabilidade das horas trabalhadas por semana além das horas contratadas, nesta instituição, vai de 2 a 30 com uma média aritmética de 7 horas. 
Tabela 2: Horas de trabalho semanais contratadas pela instituição de ensino

\begin{tabular}{c|c|c}
\hline Horas contratadas & Instituição A (\%) & Instituição B (\%) \\
\hline 15 & 0 & 10 \\
\hline 20 & 75 & 20 \\
\hline 24 & 0 & 13 \\
\hline 25 & 0 & 10 \\
\hline 30 & 0 & 7 \\
\hline 35 & 0 & 3 \\
\hline 40 & 25 & 0 \\
\hline Sem resposta & Total 100 & Total 100 \\
\hline
\end{tabular}

- Hora e local de trabalho: Na instituição A existe grande flexibilidade de horário e de local de trabalho: $88 \%$ responderam que trabalham em casa e apenas $12 \%$ permanecem na instituição. Já os da instituição B possuem menor flexibilidade de horário e de local de trabalho: 60\% responderam que podem exercer a atividade em casa contra $40 \%$ que não podem.

Pode-se supor que a grande flexibilidade de horário e local de trabalho da instituição A seja uma compensação pela falta de vínculo empregatício e dos benefícios decorrentes e também por não possuírem um NEAD, o que já não acontece na instituição $B$.

- Tempo de serviço: Observa-se pelos dados apresentados na tabela 3, que a grande maioria dos tutores estão nesta função por 1 a 2 anos. Pelas respostas abertas pode-se observar que permanecem exercendo a tutoria durante algum tempo, aproximadamente dois anos, mas depois procuram outra função, o que demonstra desmotivação com a profissão.

Tabela 3: Tempo de vínculo contínuo dos tutores com a instituição de ensino

\begin{tabular}{c|c|c}
\hline Duração & Instituição A (\%) & Instituição B (\%) \\
\hline 6 meses & 0 & 3 \\
\hline 1 ano & 0 & 27 \\
\hline 1 ano e 6 meses & 37,5 & 17 \\
\hline 2 anos & 37,5 & 13 \\
\hline 3 anos ou mais & 12,5 & 0 \\
\hline Sem resposta & 12,5 & Total 100
\end{tabular}




\title{
d) O trabalho pedagógico do tutor virtual
}

Abaixo estão relacionadas as atividades pedagógicas desenvolvidas pelos tutores virtuais nas duas instituições:

\begin{abstract}
- Atendimento aos alunos: O número de alunos por tutor virtual, nas duas instituições, varia entre 12 a 50 alunos por tutor. Não foi calculada a média aritmética do número de alunos por tutor virtual, devido a grande variabilidade numérica de um curso para outro, o que mascararia o valor único de uma média aritmética representando vários cursos. Por exemplo, existem tutores virtuais que trabalham em curso com 300 alunos, enquanto outros trabalham em cursos com 40 alunos.

- Acompanhamento de disciplinas: Na instituição A, 88\% dos tutores virtuais trabalham em uma única disciplina e $12 \%$ tutoram duas disciplinas. Já na Instituição B, 70\% dos tutores trabalham em uma disciplina e 30\% trabalham em mais de uma disciplina.
\end{abstract}

- Formulação dos conteúdos programáticos: Em ambas as instituições, 75\% dos tutores afirmaram que esta atividade é realizada pelo professor da disciplina.

- Correção e a atribuição de pontos e notas aos alunos: Na instituição A, 75\% dos tutores responderam que são os responsáveis por esta atividade e $25 \%$ responderam que dividem a atividade com os professores. $\mathrm{Na}$ instituição B,77\% dos tutores declaram serem os responsáveis pela atividade e $23 \%$ afirmaram dividir a atividade com os professores.

- Respostas as dúvidas de alunos relacionadas ao conteúdo do curso: Na instituição $A, 75 \%$ dos tutores virtuais afirmaram que são os responsáveis por responder as dúvidas dos alunos; $12,5 \%$ responderam que são os professores que realizam esta função e 12,5\% declararam que esta função é realizada por outras pessoas (coordenadores de cursos, alunos, pedagogos). Já na instituição B, $47 \%$ dos tutores virtuais informaram serem os responsáveis por responderem as dúvidas de conteúdo; $20 \%$ informaram que são os professores que o fazem e outros tipos de agrupamentos como professor / tutor virtual coordenador aparece com percentual de $33 \%$.

- Respostas as dúvidas de alunos referentes ao uso da tecnologia: Nas duas instituições, esta atividade é funçẫo dos tutores virtuais.

Outro dado importante é sobre quem auxilia os tutores virtuais no que se refere às dúvidas sobre os conteúdos dos programas dos cursos. Na instituição $A$, os tutores virtuais recorrem preferencialmente à coordenação acadêmica, como afirmado em $50 \%$ dos questionários respondidos; $25 \%$ recorrem aos professores do curso e $25 \%$ recorrem conjuntamente aos professores, coordenadores, livros e internet. Já na instituição $B, 17,5 \%$ dos tutores virtuais informaram que recorrem aos professores do curso; $17,5 \%$ a outros tutores, $20 \%$ recorrem aos livros e $45 \%$ recorrem conjuntamente aos professores, coordenadores, internet, livros e outros tutores.

e) A qualificação do tutor virtual para a função de tutoria

Em ambas as instituições, os tutores virtuais atuam em cursos correspondentes a sua área de formação. 
$\mathrm{Na}$ instituição $\mathrm{A}$, nenhum dos tutores virtuais recebe qualificação específica para trabalhar com tutoria. Já na instituição B, $50 \%$ recebem qualificação em forma de reuniões periódicas com todos os tutores virtuais, reuniões com professores e fazem cursos sobre $\mathrm{EaD}$ (recebem gratuitamente o material do curso e tem uma ajuda de $50 \%$ do valor da mensalidade do curso). Estas iniciativas têm sido muito valorizadas pelos tutores, como pode ser observado pela fala de um tutor:

Considero importante a realização de reuniões semanais com os coordenadores do curso e com os outros tutores para trocarmos experiências e tirarmos dúvidas uns com os outros, dos acontecimentos ao longo de nossa prática.

\section{f) Problemas de saúde decorrentes da prática tutorial}

$\mathrm{Na}$ instituição $\mathrm{A}, 12,5 \%$ dos tutores virtuais afirmaram ter tido problemas em decorrência da atividade de tutoria. Na instituição B, 20\% fizeram a mesma declaração. Sendo que os problemas mais apontados foram: ergonômicos, problemas na coluna e nos ombros, cansaço e problemas respiratórios quando trabalham em salas com ar condicionado constante.

\section{g) Os coordenadores dos cursos}

A seguir é apresentada uma síntese das respostas dos coordenadores das duas instituições sobre a função do tutor virtual.

De uma maneira geral, os coordenadores afirmaram que a função deste tutor é pedagógica, sendo os tutores responsáveis, juntamente com o professor e sob sua orientação, pela avaliação dos alunos, correção e pontuação das atividades avaliativas. Para os coordenadores, o tutor é um profissional coadjuvante do professor no processo de ensino e aprendizagem. Ele deve examinar o material disponibilizadoaosalunosnoambientevirtual,orientando-ossobreousodomesmo, auxiliando-os em sua adaptação nesta modalidade de aprendizagem e acompanhar as atividades realizadas pelos alunos para que se desenvolvam dentro dos prazos estabelecidos pelo cronograma do curso. Encaminhar "Comunicados" (quando o assunto for de interesse de poucos alunos), ou utilizar o "Quadro de avisos" (em caso de informações que interessem a todos), desde que previamente autorizados pelo professor ou coordenador, e prepara relatórios de acompanhamento dos alunos durante e ao final do curso. Também é o tutor virtual quem aplica provas, responde correios acadêmicos, elabora relatórios, ou seja, o tutor tem uma função administrativa e pedagógica.

No quadro 1, estão apresentadas as respostas dos coordenadores dos cursos sobre o cenário da tutoria, que complementam as informações destes coordenadores sobre a função da tutoria virtual. 
Quadro 1: Opinião dos coordenadores sobre a tutoria virtual

\begin{tabular}{|c|c|}
\hline Itens relacionados com o tutor virtual & Respostas_coordenador \\
\hline Critérios de seleção & $\begin{array}{l}\text { "A escolha é feita por meio de uma } \\
\text { seleção onde são considerados aspectos } \\
\text { relacionados à formação acadêmica do } \\
\text { candidato, seus conhecimentos sobre o } \\
\text { tema do curso e sua experiência em EaD, } \\
\text { tanto do ponto de vista pedagógico quanto } \\
\text { do tecnológico (desenvoltura no uso do } \\
\text { computador e conhecimentos relacionados } \\
\text { a essa ferramenta de ensino)." }\end{array}$ \\
\hline Perfil & $\begin{array}{l}\text { "Um tutor que desenvolve seu trabalho } \\
\text { com competência, executa bem as suas } \\
\text { funções e consegue uma boa interação } \\
\text { com os alunos fazendo com que eles se } \\
\text { interessem pelo curso e permaneçam } \\
\text { nele. Deve ser um profissional } \\
\text { aberto a mudanças, flexível e de fácil } \\
\text { relacionamento com outras pessoas." }\end{array}$ \\
\hline Formação dada & $\begin{array}{l}\text { "O tutor recebe uma formação } \\
\text { inicial, complementada durante o } \\
\text { desenvolvimento do projeto por } \\
\text { uma formação continuada, onde são } \\
\text { tratadas questões ligadas ao conteúdo } \\
\text { desenvolvido. A parte tecnológica e } \\
\text { principalmente sobre a natureza da } \\
\text { interação que desenvolve com os alunos." }\end{array}$ \\
\hline
\end{tabular}

\section{Considerações finais}

Volta-se às perguntas recorrentes, no contexto da $\mathrm{EaD}$, desde o surgimento da tutoria: qual é o papel efetivo do tutor virtual nessa modalidade de ensino? Qual é a função da tutoria? Qual é a modalidade funcional dos tutores das instituições educacionais? Os tutores desempenham uma atividade administrativa ou uma atividade pedagógica? Que tipo de formação e qualificação se faz necessária ao desempenho da tutoria? Dentro do ideário educacional construtivista, característico das mais atuais teorias psicológicas do ensino e da aprendizagem, não seriam as funções de um professor de $\mathrm{EaD}$, praticamente, idênticas às exercidas pelos tutores? Do ponto de vista das relações de trabalho no mundo capitalista, qual tem sido o lugar ocupado pelo tutor?

Estas e várias outras questões sobre o cenário da tutoria virtual foram levadas a campo, através da pesquisa junto aos tutores e coordenadores de cursos a distância de duas instituições de ensino, na cidade de Belo Horizonte - Minas Gerais. 
A partir dos dados coletados e analisados na pesquisa, conclui-se que não existem diferenças significativas nas funções desenvolvidas pelos tutores virtuais que atuam nas instituições pública e particular.

Também pode-se verificar que o tutor virtual exerce as funções pedagógicas de um professor: cumpre carga horária semanal; participa da discussão dos conteúdos programáticos e de questões administrativas; participa do planejamento das atividades acadêmicas; estabelece contato constante com os alunos; sugere e disponibiliza fontes de informação aos alunos, oferece-lhes explicações e esclarecimentos referentes ao conteúdo das disciplinas; acompanha as atividades realizadas pelos alunos incentivando-os, auxiliando-os, respondendo as dúvidas; favorece o processo de compreensão e reflexão; avalia os alunos; elabora relatórios de acompanhamento dos mesmos durante o desenrolar das disciplinas e atribui notas, além de ser o responsável pela interatividade nos cursos em EaD, pois sempre deve estar atento às necessidades do aluno, atuando como mediador entre estes e os professores, portanto, facilitando a relação interativa do processo ensino e aprendizagem.

Os tutores virtuais, embora possuam titulação e exerçam funções de professor, não recebem uma remuneração compatível com a de um professor. Quando são contratados pela instituição de ensino, ocorre sob o nome de instrutor ou como um funcionário administrativo. Levando a acreditar que é de interesse das instituições de ensino possuir um profissional menos dispendioso e que exercem funções de outros profissionais bem mais dispendiosos, sugerindo que a figura do tutor talvez tenha sido criada por uma necessidade de mercado para onde se trabalha com alunos em escala.

Portanto, percebe-se a necessidade dos tutores se organizarem para defenderem a sua real função como sendo eminentemente pedagógica e não permitirem serem contratados pelas instituições de ensino como agentes administrativos, buscando a regulamentação da sua área profissional.

\section{Referências}

ANDERSON,T. Modes of interaction in distance education: recent developments and research questions. In: MOORE, M. \& ANDERSON, W. (eds.). Handbook of Distance Education. Lawrence Erlbaum Associates, 2003, p. 129-144.

MOORE, M. G. KEARSLEY, G. Educação a distância: uma visão integrada. Tradução Roberto Galman. São Paulo: Thomsom Learnig, 2007.

MORAN, J. M. Novos caminhos do ensino a distância. CEAD - Centro de Educação a Distância. Rio de Janeiro: SENAI, 2002.

MOREIRA, M. Manual do Tutor- CEFOR. Belo Horizonte: PUC Minas Virtual, 2005.

MOREIRA, M. Manual do Tutor- CEFOR. Belo Horizonte: PUC Minas Virtual, 2007.

MUSSI, M.; HAGUENAUER, C. Comunicação e Interatividade em AVA: um estudo de caso: Disponível em: <http://www.latec.ufrj.br/revistaeducaonline/vol3_3/2.pdf>. Acesso em: 4 jul. 2011. 
RICHARDS, R. Users, interactivety and generation. New Media \& Society. v. 8. SAGE Publications. 2006. pp. 531-550. Disponível em: <http://nms.sagepub.com/cgi/content > Acesso em: 20 jan. 2011.

SILVA, M. Educação online. São Paulo: Loyola,. 2006.

SILVA, M. Sala de aula interativa: a educação presencial e a distância em sintonia com a era digital e com a cidadania. In: Boletim Técnico do Senac, v. 27, n. 2, maio/ago. 2001. Disponível em: <http://www.senac.br/informativo/BTS/272e.htm. Acesso em: 2 jun. 2010.

* Professora Doutora do Centro Federal de Educação Tecnológica de Minas Gerais (CEFET), Belo Horizonte - Minas Gerais.

** Professor Doutor do Centro Federal de Educação Tecnológica de Minas Gerais (CEFET), Belo Horizonte - Minas Gerais.

**** Aluna do Centro Federal de Educação Tecnológica de Minas Gerais (CEFET), Belo Horizonte - Minas Gerais.

\section{Correspondência}

Márcia Gorett Ribeiro Grossi - Cônsul Walter, 250/301. Bairro: Buritis, CEP: 30.575-140, Belo Horizonte, Minas Gerais - Brasil.

E-mail: marciagrossi@terra.com.br - jwcosta01@gmail.com - mmmoreira31@gmail.com

Recebido em 01 de outubro de 2012

Aprovado em 17 de junho de 2013 
